\title{
Correlation of mature mean follicle on transvaginal ultrasound and serum estradiol levels on day of trigger injection of ovulation in ovarian stimulation cycle of in vitro fertilization with retrieved oocytes
}

\author{
Avnika Kapoor*, Garima Sharma, Rita Bakshi
}

International Institute of Reproductive and Fertility Centre (IIRFT), Green park, New Delhi, India

Received: 19 November 2020

Accepted: 04 January 2021

\author{
*Correspondence: \\ Dr. Avnika Kapoor, \\ E-mail: avnika_kapoor@yahoo.co.in
}

Copyright: () the author(s), publisher and licensee Medip Academy. This is an open-access article distributed under the terms of the Creative Commons Attribution Non-Commercial License, which permits unrestricted non-commercial use, distribution, and reproduction in any medium, provided the original work is properly cited.

\begin{abstract}
Background: Controlled ovarian hyperstimulation aims to obtain mature follicles. The present study was conducted to assess the correlation of mature follicle in transvaginal ultrasound scanning (TVS) and serum estradiol levels on day of trigger injection in ovarian stimulation cycle for IVF with the oocyte yield.

Methods: In this prospective study, we evaluated oocyte donor 19 to 45 years of age who underwent oocyte retrieval at our clinic. Outcome variables like number of mature follicles visualized on TVS on the last day of stimulation was noted for all patients. On the same day, serum estradiol levels and number of mature follicles seen on TVS were noted and correlated with the number of oocytes retrieved. Ultrasound guided transvaginal oocyte retrieval was performed and total number of oocytes were noted.

Results: During the study period, 20 oocytes donors were included. Mean age of the patients was $27.9 \pm 4.7$ years. Mean BMI was $26.8 \pm 2.3 \mathrm{~kg} / \mathrm{m}^{2}$. Mean FSH level was $6.89 \pm 1.79 \mathrm{IU} / \mathrm{L}$ and mean antral follicle count on day 3 was 14.06 \pm 3.56 . On the day of trigger, mean mature follicle count seen on TVS was $20.4 \pm 13.8$, ranging from 8 to 50 . On an average, 17.2 oocytes were retrieved. On the day of trigger, mean estradiol level was $4970 \pm 203$, ranging from 500 to $15,665 \mathrm{pg} / \mathrm{ml}$. It was observed that the number of retrieved oocytes correlated significantly with the serum estradiol levels, (Pearson's coefficient 0.94, p value $<0.001)$ and number of mature follicles seen on TVS ((Pearson's coefficient 0.92 , $\mathrm{p}$ value $<0.001$ ).

Conclusions: Number of retrieved oocytes correlated significantly with the serum estradiol levels and number of mature follicles seen on TVS on the day of trigger.
\end{abstract}

Keywords: Estradiol, Intracytoplasmic sperm injection, Oocyte, Ovulation trigger

\section{INTRODUCTION}

Infertility means inability to attain pregnancy even after 1 year of regular intercourse without the use of contraception. ${ }^{1}$ Assisted reproductive technology (ART) is one treatment modality for these patients. Studies have shown that high estradiol levels on the day of trigger may result in better in vitro fertilisation (IVF) and intracytoplasmic sperm injection (ICSI) outcomes. ${ }^{2}$ The present study was conducted to assess the correlation of serum estradiol levels and number of mature follicles seen on TVS on the day of trigger with the oocyte yield.

\section{METHODS}

In this prospective study, we evaluated women aged 19 to 45 years of age who underwent IVF cycles and donated oocytes for IVF at our clinic from June 2020 till August 2020. For the study period, we had complete records of pregnancy outcomes for only 20 women, which were included in the present analysis. The study was approved 
by the institutional ethics committee. Informed consent was waived for the retrospective nature of the study, though individual patients' identifiers were coded for anonymity.

In this study, antagonist protocol was used for ovarian stimulation. The starting dose of gonadotropins [recombinant follicle stimulating hormone (FSH) and/or human menopausal gonadotropin (hMG)] was individualized according to age, antral follicle count, anti-Mullerian hormone (AMH) levels, body mass index (BMI) and previous cycles, if present for both the protocols of IVF. Thereafter the dose was adapted according to the ovarian response to treatment. In antagonist protocol, flexible regimen was used where cetrorelix $0.25 \mathrm{mg}$ was added once follicle reached 14 $\mathrm{mm}$ size. The final oocyte maturation was achieved with $0.2 \mathrm{mg}$ Decapeptyl injection trigger when at least 2 or more follicles reached a diameter of $\geq 17 \mathrm{~mm}$. Serum estradiol, luteinising hormone (LH) and progesterone levels were measured on the day of ovulation trigger.

Patient characteristics were noted and described as means and standard deviation. Outcome variables like number of mature follicles visualized on TVS on the last day of stimulation was noted for all patients. Ultrasound guided transvaginal oocyte retrieval was performed $35 \pm 1$ hour after ovulation trigger and total number of oocytes were noted. On the same day, serum estradiol levels were noted and correlated with the number of oocytes retrieved.

\section{RESULTS}

During the study period, 20 patients were included. Mean age of the patients was $27.9 \pm 4.7$ years. Mean BMI was $26.8 \pm 2.3 \mathrm{~kg} / \mathrm{m}^{2}$ and mean duration of infertility was 5.3 years. Mean FSH level was $6.89 \pm 1.79 \mathrm{IU} / \mathrm{L}$ and mean antral follicle count on day 3 was $14.06 \pm 3.56$ (Table 1). On the day of trigger, mean mature follicle count seen on TVS was $20.4 \pm 13.8$, ranging from 8 to 50 . On an average, 17.2 oocytes were retrieved. On the day of trigger, mean estradiol level was $4970 \pm 203$, ranging from 500 to $15,665 \mathrm{pg} / \mathrm{ml}$. It was observed that the number of retrieved oocytes correlated significantly with the serum estradiol levels (Pearson's coefficient 0.94, p value $<0.001)$ and number of mature follicles seen on TVS (Pearson's coefficient 0.92, p value $<0.001$ ) (Table 2 and Figure 1).

Table 1: Baseline characteristics of the patients included in the study.

Patient variables

Mean age (years)

Mean BMI $\left(\mathrm{kg} / \mathrm{m}^{2}\right)$

$27.9 \pm 4.7$

Mean duration of in

Ovarian reserve test

Follicle stimulating hormone (IU/L)

$26.8 \pm 2.3$

Antral follicle count on day 3
Table 2: Description of outcome variables.

\begin{tabular}{|c|c|c|}
\hline Outcome variables & Mean \pm SD & Range \\
\hline $\begin{array}{l}\text { Mean mature follicles } \\
\text { seen on TVS on the day } \\
\text { of trigger }\end{array}$ & $20.4 \pm 13.87$ & 3 to 50 \\
\hline Mean retrieved oocytes & $17.2 \pm 8.76$ & 3 to 48 \\
\hline $\begin{array}{l}\text { Mean estrogen levels } \\
(\mathrm{pg} / \mathrm{ml})\end{array}$ & $4970 \pm 203.05$ & $\begin{array}{l}500 \text { to } \\
15,665\end{array}$ \\
\hline \multicolumn{3}{|l|}{ Serum estradiol levels } \\
\hline \multirow[t]{2}{*}{ Retrieved oocytes } & $\begin{array}{l}\text { Pearson } \\
\text { Correlation }\end{array}$ & 0.94 \\
\hline & Sig. (2-tailed) & $<0.001$ \\
\hline \multicolumn{3}{|l|}{ Mature follicles on TVS } \\
\hline \multirow{2}{*}{ Retrieved oocytes } & $\begin{array}{l}\text { Pearson } \\
\text { Correlation }\end{array}$ & 0.92 \\
\hline & Sig. (2-tailed) & $<0.001$ \\
\hline
\end{tabular}
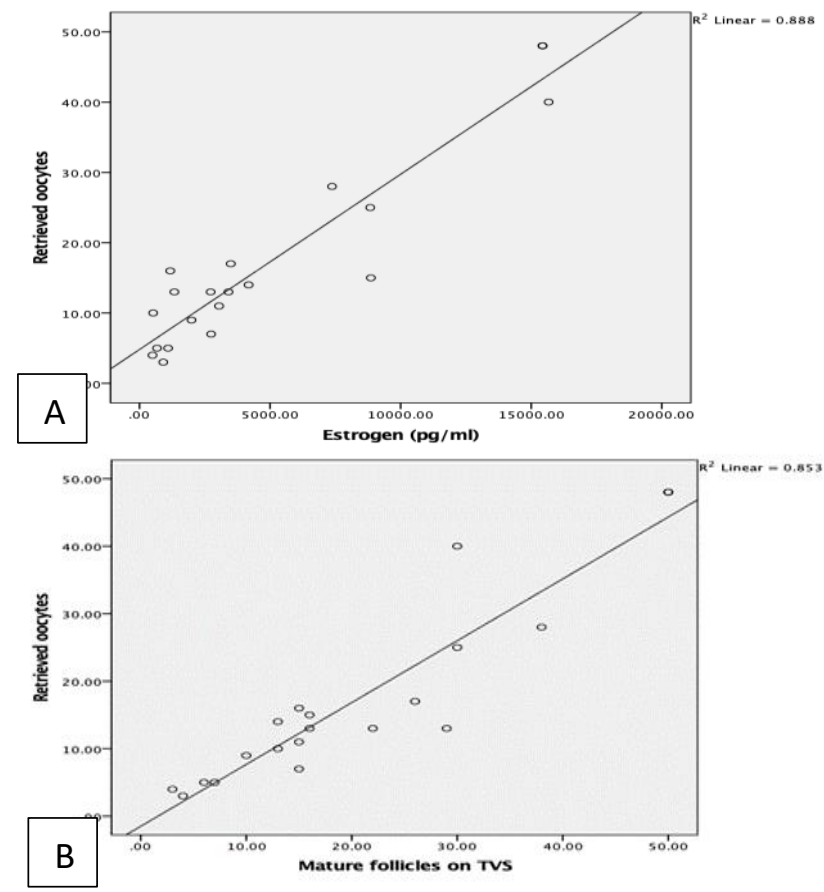

Figure 1: (A and B) Scatter plot demonstrating correlation between serum estradiol and number of mature follicles seen in TVS with number of retrieved oocytes.

\section{DISCUSSION}

The present study demonstrated a significant positive correlation between serum estradiol levels on the day of trigger and number of mature follicles seen on TVS with the number of oocytes retrieved. This finding has also been replicated in other studies. Kara et al in their crosssectional study on the association of serum estradiol levels on the day of hCG with IVF- ICSI outcome found that women who had estradiol levels $>4000 \mathrm{pg} / \mathrm{ml}$ had significantly higher number of number of oocytes retrieved (17.2 \pm 4.4$)$ compared to other groups. ${ }^{3} \mathrm{Wu}$ et al did a retrospective study on serum estradiol levels on the day of hCG and IVF outcome, in 274 IVF cycles. In that 
study, there were significantly higher oocytes retrieved in the group with estradiol levels $>5000 \mathrm{pg} / \mathrm{ml}(27.3 \pm 10)$, than other groups. ${ }^{4}$ Joo et al did a retrospective study of estradiol levels on the day of hCG and IVF outcome, in 455 fresh IVF-ET cycles. In that study, it was observed that significantly higher number of oocytes were retrieved in the group with serum estradiol levels $>4000$ $\mathrm{pg} / \mathrm{ml}(15.3 \pm 6.6)$, compared to other groups. ${ }^{5}$

Blazar et al obtained data from 1901 consecutive cycles to determine the impact of serum estradiol at the time of hCG administration on the probability of resultant ongoing pregnancy and found the mean number of oocytes retrieved increased in linear fashion with rising peak serum estradiol at all levels. ${ }^{6}$ The authors suggested that estradiol is produced by granulosa cells in the follicular phase by aromatizing androstendione to estradiol in follicular phase. These raised levels of estradiol peak increase meiotic capacity and thus enhance the oocytes maturation. Moreover, the peak serum estradiol levels maintains optimal progesterone levels during embryo implantation and the luteal phase of the female cycle.

We observed that mean age of the patients was $27.9 \pm 4.7$ years and mean BMI was $26.8 \pm 2.3 \mathrm{~kg} / \mathrm{m}^{2}$. Increasing adiposity may impact ovarian reserve, and Monica et al demonstrated a negative correlation between BMI and AMH. ${ }^{7}$ They reported that obese women had significantly lower AMH levels compared to their non-obese counterparts. Another prospective study by Rehman et al, reported that overweight women with $\mathrm{BMI} \geq 26 \mathrm{~kg} / \mathrm{m}^{2}$ had significantly decreased levels of estradiol on day 2 as well as on the day of HCG. ${ }^{8}$

There are a few limitations of the present study. First, a small sample size did not allow us to conduct sub-group analysis according to the serum estradiol levels. Second, we did not analyse the embryo quality and pregnancy rates among these patients. Last, retrospective design has inherent limitations.

\section{CONCLUSION}

Number of retrieved oocytes significantly correlated with the serum estradiol levels and number of mature follicles seen on the day of trigger. Further studies with larger sample size are required to confirm our findings.
Funding: No funding sources

Conflict of interest: None declared

Ethical approval: The study was approved by the Institutional Ethics Committee

\section{REFERENCES}

1. Zegers-Hochschild F, Adamson GD, De Mouzon J, Ishihara $\mathrm{O}$, Mansour $\mathrm{R}$, Nygren $\mathrm{K}$ et al. The International Committee for Monitoring Assisted Reproductive Technology (ICMART) and the World Health Organization (WHO) Revised Glossary on ART Terminology, 2009. Hum Reprod. 2009;24:2683-7.

2. Kosmas IP, Kolibianakis EM, Devroey P. Association of estradiol levels on the day of hCG administration and pregnancy achievement in IVF: a systematic review. Hum Reprod. 2004;19:2446-53.

3. Kara M, Kutlu T, Sofuoglu K, Devranoglu B, Cetinkaya T. Association between serum estradiol level on the hCG administration day and IVF-ICSI outcome. Iran J Reprod Med. 2012;10:53-8.

4. Wu CH, Kuo TC, Wu HH, Yeh GP, Tsai HD. High serum estradiol levels are not detrimental to in vitro fertilization outcome. Taiwan J Obstet Gynecol. 2007;46:54-9.

5. Joo BS, Park SH, An BM, Kim KS, Moon SE, Moon HS. Serum estradiol levels during controlled ovarian hyperstimulation influence the pregnancy outcome of in vitro fertilization in a concentration- dependent manner. Fertil Steril. 2010;93:442-6.

6. Blazar AS, Hogan JW, Frankfurter D, Hackett R, Keefe DL. Serum estradiol positively predicts outcomes in patients undergoing in vitro fertilization. Fertil Steril. 2004;81(6):1707-9.

7. Pasternak MC, Christos P, Spandorfer SD. The relationship between body mass index and antimullerian hormone levels in reproductive-age women; is there a negative correlation? Fertil Steril. 2018;109(3):53.

8. Rehman R, Hussain Z, Faraz N. Effect of estradiol levels on pregnancy outcome in obese women. $\mathrm{J}$ Ayub Med Coll Abbottabad. 2012;24:3-5.

Cite this article as: Kapoor A, Sharma G, Bakshi R. Correlation of mature mean follicle on transvaginal ultrasound and serum estradiol levels on day of trigger injection of ovulation in ovarian stimulation cycle of in vitro fertilization with retrieved oocytes. Int J Reprod Contracept Obstet Gynecol 2021;10:466-8. 